\title{
Gestar o real do corpo: o direito à maternidade possível
}

Compulsory adoption of children of mothers who are criminalized for being drug users: the right to maternity

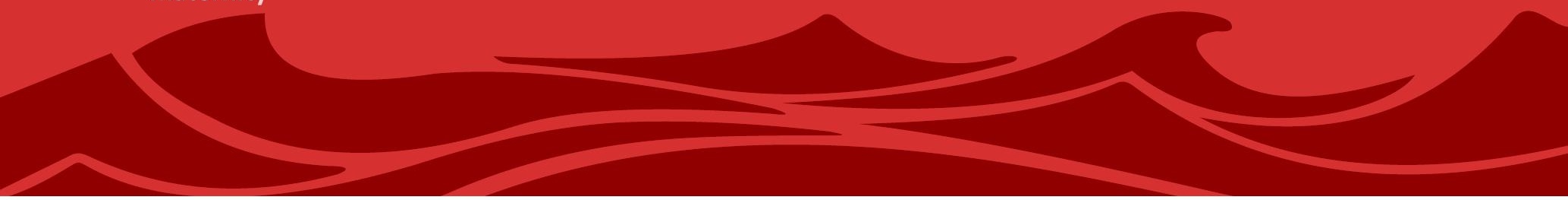

\section{Brenda Cecília'}

Assistente Social do Consultório de Rua de Belo Horizonte.

\section{Daniela Ramos Garcia'}

Arte Educadora do Consultório de Rua de Belo Horizonte.

\section{Danielle Vassalo Cruz'}

Coordenadora do Consultório de Rua da Prefeitura Municipal de Saúde de Belo Horizonte.

E-mail: coordenacaoconsultorionarua@ pbh.gov.br

\section{Eduardo Ornelas de Oliveira'} Psicólogo do Consultório de Rua de Belo Horizonte.

\section{Flávio Ricardo Santos da Sila'}

Redutor de Danos do Consultório de Rua de Belo Horizonte.

\section{Resumo}

Os autores apresentam narrativas e relato de vivências a partir das histórias dos sujeitos acompanhados pelo Consultório de Rua, dispositivo da Rede de Saúde Mental de Belo Horizonte, apresentando o "retrato" de mulheres gestantes nas cenas de uso de drogas. Violência de gênero, racismo e criminalização da pobreza são temas transversais à vida destas mulheres, que precisam fazer um esforço descomunal para tentar garantir o direito de
Heloísa Helena Maria'

Assistente Social do Consultório de Rua de Belo Horizonte.

\section{Isabel Magalhães da Silva'}

Assistente Social do Consultório de Rua de Belo Horizonte.

\section{Júlio César Amaro'}

Arte educador do Consultório de Rua de Belo Horizonte.

\section{Júnia Vanessa Costa'}

Enfermeira do Consultório de Rua de Belo Horizonte.

\section{Rosimery lannarelli'}

Assistente Social do Consultório de Rua de Belo Horizonte.

\section{Roberta Kelly Soares Oliveira'}

Enfermeira do Consultório de Rua de Belo Horizonte.

permanecer com a guarda de seus filhos gestados.

Palavras-chave: Redução de Danos; Gestação; Violência; Vulnerabilidade social.

\section{Abstract}

In this paper, the authors present a "portrait" of drug dependent pregnant women through the narratives, experiences and life stories of the individuals seen by the multidisciplinary team of 
the Consultório de Rua. The health service aims to reduce the negative consequences of drug use for people living on the streets as part of Belo Horizonte Mental Health Program. A profile of the drug dependent pregnant women in their challenge to maintain custody of their children

\section{Introdução}

"Quando, seu moço, nasceu meu rebento Não era o momento dele rebentar Já foi nascendo com cara de fome E eu não tinha nem nome pra lhe dar Como fui levando não sei lhe explicar Fui assim levando, ele a me levar" ${ }^{11}$ (Chico Buarque)

Desde quando foi declarada a "Guerra às drogas", por Richard Nixon, em meados de 1971, temos observado o aumento da política repressiva do Estado nos territórios de maior vulnerabilidade social. $\mathrm{O}$ discurso de combate às drogas legitima que corpos sejam regulados e combatidos, como se dá em uma situação de "guerra". Karam² nos alerta:

Os alvos nessa guerra são os mais vulneráveis dentre os produtores, comerciantes e consumidores das drogas proibidas; os "inimigos" nessa guerra, são seus produtores, comerciantes e consumidores pobres, não brancos, marginalizados, desprovidos de poder. ${ }^{2: 3}$

Estabelecer o perfil do "alvo a ser combatido" é demarcar o recorte da criminalização do negro e pobre, tendo como efeito o genocídio e o encarceramento em massa de jovens negros, principalmente, oriundos das favelas das grandes cidades, geralmente considerados associados ao crime e ao tráfico de drogas, como colocado por Reis: ${ }^{3}$ despite living in circumstances defined by violence against women, criminalization of poverty and racism is addressed.

Keywords: Harm reduction; Pregnancy; Violence; Social vulnerability.
Os homicídios, não afetam as diferentes parcelas da sociedade com a mesma intensidade [...]. Estudos têm demonstrado que os jovens, principalmente os do sexo masculino, são os mais expostos à violência, sendo também a população na qual a taxa de óbitos por homicídios é maior (WAISELFISZ, 2012). Dentro desta sub-população há outra ainda mais vulnerável: os jovens negros. Os jovens negros são marcados por escassas oportunidades de estudo, trabalho e lazer e são as maiores vítimas de mortes por agressão no Brasil. $^{3: 23}$

Para os jovens negros moradores das periferias o Estado chega através da repressão, ficando em segundo plano a oferta de políticas públicas de garantia de direitos. Em concomitância ao genocídio desses jovens, temos observado também a criminalização das famílias pobres que tem sido, em inúmeras situações, punidas pela falta de responsabilidade das políticas públicas ao não garantirem acesso a direitos básicos como educação, saúde e habitação. As medidas tomadas, muitas vezes, reforçam ainda mais a vulnerabilidade em que essas famílias se encontram e contribuem sistematicamente para a criminalização da pobreza.

A chamada guerra às drogas, ao legitimar a guerras aos pobres e negros, também se 
expressa na violência de gênero ao potencializar, de diversas formas, a violência contra a mulher pobre. E, é sobre a especificidade das violências vivenciadas pelas mulheres pobres usuárias de drogas e em situação de rua acompanhadas por um dispositivo público da saúde mental em uma capital brasileira, que iremos dissertar no presente artigo.

Em Belo Horizonte, capital de Minas Gerais, é notável que a presença de mulheres nas cenas públicas de uso de drogas vem crescendo de maneira exponencial, mas o que as tornam alvo de atenção nas cenas e nas políticas públicas não é o fato de ficarem mais vulneráveis morando nas ruas, inclusive sendo constantemente vítimas de violência sexual, mas sim o fato de essas mulheres, cada vez mais, se apresentarem nesses espaços em estado de gestação. A partir disso, gestar na rua, tornou-se mais um motivo de criminalização, em especial, da mulher pobre. Principalmente, quando, em julho de 2014, o Ministério Público da Vara da Infância e Juventude Cível de Belo Horizonte, cria duas recomendações 5 e 6, que, posteriormente, em julho de 2016 se tornam uma portaria, para mais uma vez lançar as mulheres na roleta russa da violência e criminalização da pobreza: o não direito à maternidade. A Portaria ${ }^{4}$ fecha portas em vez de abri-las. Não há espaço para singularizar cada caso e nem para gestar, apenas para o estigma e preconceito daqueles que se drogam ou já se drogaram. O que fazer? O tempo passa muito rápido, a gestação curta (não chega a 37 semanas), hormônios a todo vapor, risos, lágrimas, ideias, medos, sonhos, conversas, cuidados, insegurança e, inevitavelmente, a entrada na maternidade. Tem início outra etapa: o parto e a peregrinação da saída da maternidade, com um agravante, muitas vezes, sem os filhos nos braços.

É diante desse trágico contexto, que se delineiam as narrativas que iremos ler sobre mulheres em que a violência de gênero contribuiu, da maneira mais radical, para a fragilização ou rompimento dos laços familiares e, consequentemente, a ida para as ruas, espaço em que serão mais uma vez violentadas. A vulnerabilidade social em que essas mulheres se encontram, sustenta, mais uma vez, o sistema capitalista, racista, machista e patriarcal.

As narrativas aqui traçadas foram coletadas pelos profissionais trabalhadores do Consultório de Rua SUS BH, da Rede de Saúde Mental da Prefeitura Municipal de Belo Horizonte. O dispositivo foi implantado em 2011, cuja proposta é atuar no espaço da rua, ofertando cuidado em saúde aos sujeitos que fazem uso de álcool e outras drogas nas nomeadas "cenas de uso". Ou seja, que fazem uso da droga nas ruas da cidade. O Consultório de Rua BH se orienta pela lógica da Redução de Danos e Reforma Psiquiátrica. Philipe Lacadée, ${ }^{5}$ em 2013, ao conhecer o trabalho, coloca algo fundamental na condução das equipes, que é a oferta de um espaço de fala e escuta dos sujeitos inseridos nessa cena. Ele nos alerta 
que: “Não existe preservativo para a língua (...) para além do objeto preservativo, poder oferecer a elas [usuárias] alguma coisa de essencial, isto é, sua presença (...). É o ser que elas [técnicas] oferecem, seres de fala". É o corpo dos técnicos do Consultório de Rua, nas cenas de uso, que proporcionam espaços para circular a vida palavreada, momento de intervalo entre uma pedra e outra, entre um thinner e outro, inaugurando a entrada de outros objetos e de outra relação com a cidade através do pincel, tintas, cinema, parques, museus e máquinas fotográficas.

Rosimeire Silva, ${ }^{6}$ ao descrever o Consultório de Rua, afirma que é nas "andanças pelos becose ruas ao lado de usuários de álcool e outras drogas, que vamos cuidando, recolhendo palavras, resíduo humano que ajuda a tecer o laço, e aprendendo com o que a realidade nos

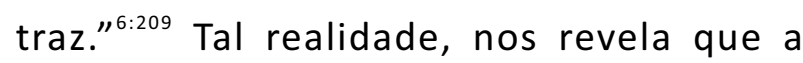
construção de um projeto terapêutico só é possível a partir da clínica do singular, entendendo o modo como cada um se apresenta e se relaciona com o Outro. É na perspectiva de se apresentar como um outro possível que enlaça com a vida, que o Consultório de rua se apresenta nas cenas de uso de drogas e na rede de saúde e assistência pública.

O resultado da elaboração das narrativas de mulheres que, nas cenas de uso de drogas, porventura, amam, sonham e engravidam, só foi possível a partir da escuta e do comprometimento ético das equipes do
Consultório de Rua $\mathrm{BH}$, ao tentar garantir o direito dessas mulheres serem mães. $O$ que se nota ao perceberem os primeiros sinais da gestação, é a alegria, o sonho e a esperança se mesclarem ao medo e a incerteza do futuro. Diante do receio dos serviços de saúde notificarem à Vara da Infância e Juventude, algumas mulheres consentem somente aproximação do Consultório de Rua, que se apresenta como um ator primordial para o laço com essas mulheres gestantes. Provavelmente pelo fato do serviço estar na rua, mais próximo ao real de suas vidas, chegando com muita delicadeza e com a ética decidida do cuidado em liberdade.

Ao longo dos seis anos do serviço na capital mineira foram presenciadas muitas histórias de perda, das quais aqui serão relatadas duas delas. Apesar disso, com o passar do tempo, as equipes foram aprendendo sobre o fazer na rua com os sujeitos que nela vivem. Em concomitância a isso, houve a conquista de experiência no que se refere à força da articulação dos casos em rede; demonstrando os efeitos que se produzem ao garantir o direito dessas mulheres ressignificarem suas vidas a partir da maternidade possível à cada uma e, poderem, de fato, "ganhar os filhos" ao entrar na maternidade. Desse modo, foi possível eleger dentre dezenas de experiências exitosas, duas narrativas sobre mulheres que, junto ao Consultório de Rua, conseguiram alcançar o direito ao convívio familiar com seus filhos, o qual é previsto no Estatuto da Criança e do Adolescente-ECA. 
É importante destacar que as 4 narrativas que serão apresentadas, a seguir, se inserem na pesquisa nacional denominada Criação de Observatório Microvetorial de Políticas Públicas em Saúde e Educação em Saúde, iniciada em 2013,' aprovada pelos Comitês de Ética em Pesquisa em nível nacional (CEP: 1756736/2016), pela Secretaria Municipal de Saúde de Belo Horizonte (CEP 1847486/2016) e Universidade Federal de Minas Gerais (CEP 2264660/2017). Durante a coleta de dados foram respeitados os preceitos éticos internacionalmente recomendados para estudos envolvendo seres humanos. O Termo de Consentimento Livre e Esclarecido - TCLE foram ofertados e aceitos por todos os participantes das entrevistas para a escrita das narrativas, garantido assim, o direito à informação, à participação ou não na pesquisa, além do anonimato dos sujeitos mencionados pelas narrativas.

\section{Narrativas}

\subsection{Joana: a judicialização do afeto}

Joana" é uma jovem mulher de 36 anos. Teve gestações anteriores, mas foi nos últimos três anos que conheceu seu atual companheiro, por quem se apaixonou. Fruto deste relacionamento teve uma gravidez ao final de 2014. Estava em situação de rua. Procurou-nos para darmos início ao pré-natal. Entre as consultas, iniciou o processo de organização de uma moradia e preparativos para receber o bebê. Cada pecinha de roupa era uma conquista, um laço que se fazia e uma inscrição da maternidade. Antes que terminasse os preparos, pariu um menino saudável. A Vara da Infância e Juventude foi notificada, separando mãe e filho. E Joana é reconhecida apenas pela nomeação de "usuária de drogas", apagando qualquer outra construção feita por ela, como a sustentação do desejo de ser mãe e a organização que ela fez em torno disso. Os laços com o filho, antes fortalecidos a cada semana, deram lugar a uma distância, inclusive física. A frieza do protocolo de visitação, a distância territorial do abrigo para o local de moradia, as entrevistas constrangedoras a que era submetida, na tentativa de judicializar seu afeto, a fizeram sucumbir. Joana não conseguiu romper tantas barreiras e a criança foi para adoção. Momentos duros para essa mulher que depositava no filho a esperança da reconstrução de família. Deprimiu-se, tentou tratar este sintoma através da droga e, não conseguindo, atentou contra a própria vida. Momento em que se esquivou da nossa abordagem nos pontos onde a encontrávamos.

A vontade de ter um filho a fez engravidar novamente no início de 2016, demorando a iniciar o pré-natal por medo de, mais uma vez, perder o direito a ser mãe. Quis se organizar primeiro. Alugou uma pequena casa na comunidade, procurou o Centro de Saúde e, por não estar mais em situação de rua e nem fazendo uso de drogas, afastou o Consultório de Rua, exceto em situações pontuais. Na mesma maternidade, pariu uma menina saudável. Desta vez, o parto foi cesáreo e com laqueadura. 
Durante o período de internação e mesmo após sua alta, comparecia diariamente para amamentar. O esforço desta mulher era notável. Queria muito sair da maternidade com sua filha nos braços. Respondeu às várias abordagens da equipe do hospital, colheram todos os dados. A família extensa foi acionada, respondendo aos encaminhamentos, mas parece que não de forma suficiente para o ideal de "maternidade" construído na sociedade contemporânea. Em uma sexta feira, pela manhã, ao se apresentar para amamentar, teve a notícia do abrigamento da criança. Para onde foi sua filha? O que fazer com o leite escorrendo das mamas? Perguntas sem respostas. Saiu desesperadamente em busca de ajuda. Foi difícil articular as permissões necessárias para o encontro entre elas. "Só na segunda-feira" disseram. Uma espera sem fim... Depois de muitas articulações veio autorização para visitação: "Uma vez por semana e com duração de uma hora". A burocracia não anda na mesma velocidade dos sentimentos e da angústia. Os dias se arrastam sem solução. As forças vão se esvaindo... Do lado de cá, continuamos resistindo e lutando para um desfecho que, de fato, possa garantir o direito desta mulher ao exercício da maternidade. [O Caso continua em aberto].

\subsection{Luana: melhor um filho morto, do que um} filho com a família extensa

Luana'". Mulher de 30 anos, portadora de sofrimento mental. Nasceu na rua e vive nela desde então. Sua mãe, ao superar a trajetória de vida nas ruas, fica com a guarda da filha de
Luana. A rua estava enraizada demais para que ela conseguisse superá-la. Assumiu a maternidade possível naquele momento. Via a filha de tempos em tempos e falava dela com afeto, ressaltando sempre que era muito bem cuidada pela avó. Luana apresenta algo de interessante na relação com a rua: nunca a vimos fazer uso de drogas, mesmo estando constantemente nas cenas de uso. É sempre um corre-corre, recolhendo materiais recicláveis e de alguma forma recolhendo algo da sua história. A fala vacila, meio gaguejante. Difícil dar lugar à voz diante de tantas violências... Relações abusivas com os nomeados companheiros vão constituindo seu modo amoroso de se relacionar. O corpo sempre exposto para que o outro fizesse o que dele quisesse, cortes nesse corpo tão violentado, vão sendo substituídos por novas costuras que amarram algo para este sujeito. É neste momento que Luana engravida de novo e inicia um momento de autoconhecimento, algo vacila na construção já realizada anteriormente. Inicia o pré-natal, começa a questionar a violência do atual companheiro e apresenta uma fome nunca antes sentida! A fome da vida refletida no consumo dos alimentos, "às vezes como quatro pães ao mesmo tempo", "estou ganhando corpo", dizia. Sim! O corpo ganhava consistência!

Luana foi acolhida na maternidade para dar continuidade ao pré-natal. Pôde dizer que este seria seu último filho, "ou vocês acham que quero abrir uma creche?". Em determinados momentos tentou se organizar para ficar com a 
guarda. Estava morando na casa da família do companheiro, mas era uma casa como Vinicius de Moraes ${ }^{8}$ já cantou, "não tinha teto não tinha nada". E construir algo a partir do "nada" seria muito difícil naquele momento. Mas Luana não desiste e mais uma vez constrói a maternidade possível: a mãe ficaria com a guarda e ela ajudaria nos cuidados.

Fizemos um chá de bebê. Teve muito lanche e vários embrulhos em papéis coloridos. Ao abrir cada um, os tocava, sentia o cheiro e dizia como o filho iria usar tudo aquilo. A criança foi abrigada e Luana ia constantemente visitá-lo. Sua mãe estava se organizando para ficar com a guarda, e, sem aviso prévio, a visita de Luana foi proibida, bem como a possibilidade de adoção pela família extensa. Pouco tempo depois teve a notícia de que aquele que escolheu para ser seu último filho tinha morrido na instituição. Não foi dado a ela o direito de enterrar e elaborar o tão doloroso luto do filho retirado e morto. 0 discurso da suposta proteção falhou e foi letal neste caso!

A concretude da morte de seu filho só veio com o atestado de óbito, retirado muitos meses após na Defensoria Pública. E chorou, chorou muito, como se tivesse sido ontem. Por vezes, nos traz a mesma demanda: exame para detectar gravidez. Como estar grávida se fez a laqueadura? "Será que fizeram mesmo a ligação de trompas?", indaga. Para ela algo que ligaria, na verdade, desconectou. As lembranças do filho e a impossibilidade de elaborar o luto a fazem estar em constante gestação, e seu corpo dá prova disso: ainda produz leite e o abdômen continua distendido, como de uma gravidez.

2.3. Janaína: dos enganos da morte à escolha pela vida

Janaina ${ }^{\mathrm{IV}}$ teve seu primeiro contato com o Consultório de Rua em meados de agosto de 2012, na região das casinhas, local de grande vulnerabilidade e exclusão social, tendo como consequência a violência, uso e abuso de drogas e tráfico. A mesma circulava em diferentes pontos do território, que se divide entre uma extensa área verde com lagoa e escombros do antigo clube desativado ACM (Associação Cristã de Moços) e os becos e vielas construídas a partir do financiamento do $\mathrm{BNH}$ (Banco Nacional de Habitação). Nestas cenas, onde o tráfico é intenso, o esgoto é a céu aberto, há declives, entulhos, mato, malocas de madeirite instaladas em uma linha, onde de tempos em tempos, passa um trem. Tudo isso em um local onde crianças e adolescentes da comunidade soltam papagaios no inverno. Algo de singular nestas cenas é um certo silêncio velado. Fala-se, mas pouco se diz.

Durante uma oficina de vídeo realizada pela equipe do Consultório de Rua, Janaína se apresenta queixosa e gritando devido a "fortes dores que foram causadas no momento em que não foi respeitada como mulher e sofreu abuso e violência sexual", por isto era necessário atendimento médico. Ela chorava com a mão no baixo ventre, dizendo que 
"estava morrendo e que precisava de auxílio da equipe". A partir deste dia, o vínculo com Janaína foi estreitado, ela demandou ser acompanhada de volta para a sua casa. Este foi o momento em que foi possível, a partir da escuta, entender um pouco mais o que de singular tem em sua história.

Janaina nos contou que foi casada, conheceu o pai de seu filho na cena de uso. Assim que engravidou foi morar com ele e a sogra. Durante a gravidez ele ficava com ela a todo o momento, entretanto, quando o filho Luiz nasceu, o pai "passou a frequentar as ruas e às vezes ficava dias sem aparecer em casa, usando drogas ou saindo com outras garotas". Sobre seus pais, Janaína relata que sua mãe "bebia muito, saía de casa e não aparecia para cuidar dela". Por isso, foi criada pelo pai e pela avó paterna, a qual considera como mãe. Janaína mencionou que "foi o xodó da família, que todos a criaram com muito carinho e afeto". Disse "não se lembrar como sua mãe biológica faleceu" (sic), mas acha que foi em uma dessas idas para a rua. Quanto ao falecimento do pai não conta a história, apenas destaca "sentir muita falta do dele".

Ao refletir o trabalho do Consultório de Rua, que se insere na política de Redução de Danos, a equipe avaliou que era interessante ampliar os pontos de circulação de Janaína pela cidade. Pautados na clínica, garantia de direitos e ação de promoção e autonomia, a equipe a acompanhou em um passeio no Parque das Águas, oportunidade/momento em que ela expressou suas aflições e desejos.
Janaína transitava as cenas de uso e sua casa. Certa ocasião, "uma amiga, que se assemelhava fisicamente com ela, foi assassinada por engano pelos traficantes da região das Casinhas". Ela estava usando uma touca de Janaína, pertence que a identificava. O fato fez Janaína retornar para casa, ao realizar a escolha de permanecer viva. Passados três meses Janaina retornou à cena de uso, com o habitual comportamento falante, excessiva, oscilando entre rua e casa. Nesse ínterim surgiu uma suspeita de gravidez. A equipe a acompanhou ao Centro de Saúde onde o exame constou resultado positivo. Ela reagiu dizendo: "quero ir embora para casa, não vou ficar com este bebê".

Mesmo não se conformando com a gravidez, porque "não estava preparada", e a todo o momento isso era demarcado, inicia o pré-natal tendo como efeito a diminuição da sua frequência na cena de uso. Em uma das idas ao pré-natal Janaina menciona que "caso tivesse uma vida diferente até poderia ficar com o bebê, mas teme que jamais pudesse exercer a guarda da criança, por ser usuária de drogas".

Em fevereiro de 2015, Janaína entrou em trabalho de parto. Ela, que falava não querer ficar com o bebê, ao ver a menina, retifica sua posição. Como estratégia, a maternidade aciona a família extensa. Após várias discussões de caso com a maternidade e outros dispositivos da rede, foi acordado entre os equipamentos que ela sairia com o bebê, o qual ficaria sob os cuidados do tio, que residia próximo à casa de Janaina, contribuindo para 
uma maior aproximação entre mãe e filha.

Ainda na maternidade, Janaína conta para a equipe, que há cerca de oito anos, teve um namorado, o qual ela amava muito, mas que fora assassinado, por engano, pela polícia. Tal fato marcou sua vida, de modo que Janaína relata que "nunca mais amou ninguém, sem ele a vida perdeu completamente o sentido. Não tinha forças para viver e era muito difícil falar sobre o ocorrido". Depois de chorar muito se acalmou e pegou sua filha para amamentá-la.

Após essa gestação Janaina afirmava que não desejava ter mais filhos. Diante da sua vontade foi realizado o método contraceptivo (DIU), enquanto aguardava o procedimento da laqueadura. Janaína retornou para a casa da avó, começou a frequentar outra cena de uso, conheceu seu atual companheiro e passaram a viver juntos como "marido e mulher". A partir desse acontecimento, Janaína afirmava não fazer mais uso de crack e planeja constituir uma nova família ao decidir retirar o DIU, engravidando logo em seguida.

Sendo assim, o Consultório de Rua se compromete a acompanhá-la durante a gestação, garantindo tarifa social para o deslocamento até o Centro de Saúde e eventualmente indo com ela às consultas de pré-natal. Durante esse período a equipe foi acionada pelo Serviço Social do Hospital que julgava necessária uma discussão "por se tratar de uma ex usuária de drogas". Como encaminhamento da reunião, foi acordado que os serviços ficariam na retaguarda do cuidado com a família. Quando a criança nasceu, foi solicitado ao Consultório de Rua que elaborasse um laudo comprovando o acompanhamento da gestante e atestando seu comparecimento às consultas pré-natal. Com o laudo feito e entregue ao hospital, Janaina pôde sair da maternidade na companhia de sua filha.

Atualmente Janaina e família são acompanhadas pelo Centro de Saúde, encontrando a equipe do Consultório de Rua esporadicamente em eventos pela cidade. Ao expressar a certeza de que não gostaria de ter outra criança, Janaína, mais uma vez, é acompanhada pela equipe durante o processo de laqueadura. Entre momentos de "engano" em sua história, que tiveram como consequência a morte: do companheiro que era o amor de sua vida e da amiga que morreu em seu lugar, Janaina ressignificou a vida a partir da última gestação.

\subsection{Maria: o resgate do bebê}

Quando conhecemos Maria, 35 anos, ela fazia uso de substâncias psicoativas e se encontrava em um dos territórios de atuação do Consultório de Rua, onde todo o processo de seu cuidado se deu na perspectiva da redução de danos. Maria estava na terceira gestação. Tinha uma filha de quatorze anos, que foi fruto da primeira gestação. A segunda gestação apresentou certas intercorrências: seu bebê crescia em suas trompas, o que a levou a sofrer um aborto. A terceira gestação foi a do Bruno, 
sobre a qual iremos tratar ${ }^{v}$.

A equipe por vários momentos tentou acompanhar Maria até o Centro de Saúde para realização do pré-natal. Entretanto, ela não se abria muito e só aceitava nossa oferta de insumos. Com o tempo, já nem conseguíamos avistar Maria no território.

O que mais nos chamou atenção neste caso foi o ponto até onde chegou: Maria efetuou o "sequestro do seu próprio bebê". Devo dizer que, assim que ela chegou à maternidade, foi informada de que não poderia levar seu filho daquela instituição. Devido a isto, ela mesma planejou o "sequestro" do seu próprio filho. E assim o fez Maria, que saiu do hospital pela portaria principal com seu filho em uma sacola.

Após o ocorrido, o Consultório de Rua foi informado pelo Centro de Saúde, que Maria havia fugido com seu filho, e nos apresentaram a demanda de que ela fosse encontrada para continuidade do cuidado. Quando a avistávamos, esta não nos contava onde estava seu filho, nem mesmo mencionava nada em relação ao assunto. Até que alguns meses depois, recebemos uma ligação do Centro de Saúde com a seguinte informação: apareceu o filho "sequestrado". Ele veio com os familiares para fazer avaliação de saúde. Foi discutida no Centro de Saúde a importância de não se reprimir a família, e sim acolher e oferecer os cuidados necessários. Assim, buscamos pactuar com o Centro de Saúde uma ação conjunta, no acolhimento de Bruno. Com isso, a família continuou levando a criança ao Centro de Saúde, que assumiu seu acompanhamento. O foco do trabalho em conjunto se deu no sentido de garantir que a família extensa formalizasse a guarda da criança.

\section{Uma nova gestação}

E agora? Agora Maria está grávida de novo, de seu filho Lucas. Nesta quarta gestação, Maria aborda o Consultório de Rua demandando a realização do pré- natal. Maria desabafa com a equipe: "Eu não vou sair desta vez com meu filho na sacola. Desta vez, vou sair com ele no colo".

Chegamos a acompanhar Maria em uma consulta de ultrassom na maternidade, onde ela havia ganhado seu último filho. Ao encontrar os profissionais da maternidade, ela disse: "Eu estou com o Consultório de Rua, e desta vez eu não sairei com meu filho em uma sacola". Este foi um marco muito importante ao nosso ver, pois apontava que esta gravidez, este lugar de mãe, era um novo lugar e um novo momento.

Por estar com medo de ser reprimida pela maternidade onde ganhou Bruno, e onde recebeu a alcunha de quem havia "sequestrado" o próprio filho, Maria pretendia ganhar o Lucas, em outra maternidade. No entanto, tivemos a notícia repentina de que Maria havia dado à luz na mesma maternidade. Ao chegarmos no hospital, os profissionais colocaram para o Consultório de Rua: "Olha, 
daqui ela não foge. Todos estão de olho nela! A segurança está redobrada. Todos já sabem do histórico dela. E outra coisa, ela não se abre, ela simplesmente é fechada, ela é fria, ela é diferente das outras mães. Ela não pôs nem o nome no filho dela". Quando o Consultório de Rua chega no quarto dela, a primeira coisa que perguntamos é: "Qual o nome do bebê?" A mãe responde: "Eu estava esperando vocês chegarem para nós escolhermos juntos".

\section{Um novo arranjo para seu filho}

A partir do dia que visitamos Maria, o Consultório de Rua se debruçou no caso e não se afastou do hospital. Maria nos chamou novamente para conversar, pediu para que chamássemos sua família e comunicou: "Olha, eu não dou conta de ficar com o Lucas. Mas eu não dou os meus filhos para os outros. Os meus filhos têm que ficar próximos, onde eu possa visitá-los. Eu quero que a minha família fique com ele, pois eles cuidam tão bem de Bruno".

Maria teve alta no dia 19, mas se recusou a sair do hospital sem a presença do Consultório de Rua, o que ocorreu no dia 21. Neste momento houve muitas dificuldades em relação ao registro da criança. Os profissionais do hospital não permitiram que ela registrasse o seu filho, pois diziam que não tinham garantia que a certidão de nascimento apresentada por Maria realmente fosse dela. Impediam o registro da criança dizendo: "Mas o nome da mãe de Maria está errado na certidão". Então respondemos: "Nós nunca atendemos a mãe dela. Nós conhecemos a Maria, e esta é a Maria. Então, porque ela não poderá registrar o seu próprio filho?" Fomos impedidos de acessar a documentação necessária para a confecção da Certidão de Nascimento e nos deparamos com o seguinte recado: "é, não vai adiantar nada não". Resolvemos não recuar e com muita insistência formalizamos que reconhecíamos a paciente como Maria e, finalmente, ela conseguiu a liberação para registrar seu filho. Ligamos para a família, que havia "acampado" na portaria do hospital. A família subiu e, junto com os técnicos do Consultório de Rua, assinaram a documentação necessária para a Certidão de Nascimento de Lucas.

A equipe então, acompanhou Maria até a residência de sua família, onde cuidaram dela no pós-parto. Na saída do hospital, a irmã de Maria disse: "meu coração aperta em deixá-lo pra trás". Maria solicita aos técnicos de enfermagem "cuidem bem do meu filho, está ficando um pedaço de mim aqui". O bebê permaneceu na maternidade até a equipe médica informar que o recém-nascido já teria condição de alta clínica, apesar da necessidade de dar continuidade ao tratamento de sífilis no Centro de Saúde. Entretanto, o serviço social da maternidade reteve a criança para acionar à Vara Cível da Infância e Juventude, ignorando a família extensa.

Diante disso, a rede municipal de saúde realizou uma reunião com Consultório de Rua, Centro de Saúde, Coordenação de Saúde Sexual e Reprodutiva, e GERASA - Gerência de 
Saúde Regional. Desta reunião foi elaborado um relatório, que foi enviado para a Maternidade informando que a rede estava integrada e articulada em torno do caso e avaliava, naquele momento, que a família extensa poderia ficar com a guarda. Sem retorno da maternidade sobre a conduta que iriam adotar, a família, permaneceu na porta do hospital, quase diariamente. Era visível a persistência dessa família.

A disputa pelo direito de não dividirem uma família

A equipe do Consultório de Rua teve muitos impasses. Em vários momentos se deparou com profissionais que não acreditavam no caso. A partir do momento que as articulações iam caminhando no sentido da família assumir a guarda da criança, surgiram várias dificuldades apontadas pelo Conselho Tutelar, como o fato de as outras crianças da residência da família não estarem frequentando a escola. Entretanto, o Consultório de Rua, mais uma vez, não recua, se mantendo ao lado da família, na sustentação do desejo e do direito da família ficar com a guarda da criança. Assim, quando falaram com a gente para "pularmos fora", é aí que "pulamos para dentro" do caso. Foi um momento importante para a equipe quando perguntarmos um para o outro: "Se eu pular, você me pega?" A resposta foi: "Sim". Então pulamos todos juntos.

A família enfrentou outros impasses graves, como a proibição das visitas de Maria ao Lucas na maternidade. Diante disso, o Consultório de Rua orientou e acompanhou a família até a Defensoria Pública. Descobrimos que o filho de Maria estava abrigado e o Consultório de Rua prossegue nos trâmites, entre a família, defensoria e abrigo. Daí então, a Defensoria nos faz a seguinte demanda: "Quero que vocês apresentem um relatório. O Consultório é o único equipamento que aponta questões positivas dessa família extensa. Gostaria de saber o por quê". Respondemos: "Porque o Consultório de Rua entra em locais que nenhum outro serviço entra".

Elaboramos o relatório e realizamos o acompanhamento sistemático tanto da usuária quanto de sua família. Observamos então, que alguns profissionais da maternidade consideraram que a família não estava apta para ficar com o Lucas, por preconceito em relação ao local de moradia da família.

O Consultório de Rua se apresenta em uma audiência preliminar, onde fomos ouvidos pelo juiz. Várias perguntas foram feitas a respeito da usuária e sua família. Defendemos então, que a família descrita pelo histórico do hospital não era a mesma que acompanhávamos. Isso inaugura algo novo para o Consultório de Rua, porque este equipamento nunca havia participado de uma audiência para guarda de um filho. Durante a audiência tivemos a oportunidade de mostrar as fotos que registraram todo o acompanhamento da usuária. Fotos muito espontâneas de Bruno, o irmão mais velho de Lucas, que está com a 
família e é muito bem cuidado. Não há qualquer espécie de maus tratos presenciados pela equipe. As fotos foram incluídas no processo. Finalmente, após todas essas dificuldades vivenciadas, podemos ver esta fotov', que é o dia que nós recebemos a notícia que a família extensa ficaria com a guarda provisória de Lucas. A gente estava esperando a ligação da defensora, mas quem nos avisou foi o abrigo.

Neste momento, todos no auditório ficam curiosos para entender as justificativas para o abrigamento da criança e da audiência para sua guarda na família. Vários profissionais do Consultório de Rua retornam: Pobreza.

\section{O "começo"}

A assistente social da equipe do Consultório de Rua apresenta uma foto da família e diz: A foto que colocamos aqui é o começo. Por quê? Porque é a partir deste momento que o Consultório de Rua acompanha a inserção da família no CRAS VII, no Centro de Saúde, e encaminha as adolescentes para estagiar na Cruz Vermelha. Há uma boa conversa com o Conselho Tutelar e envolvimento do CERSAM $A D^{\text {VIII }}$ no caso. Então, realmente é estabelecido um começo de uma nova inserção da família na rede. Estes são mais alguns momentos (mostrando novas fotos) de organização da família. Motivo pelo qual questionávamos o porquê da retirada da criança da família. Observamos nestas fotos a família se organizando, comprando berço, comprando tudo. Lembro da indagação de Bruno sobre seu irmão Lucas: "Cadê o meu irmão que não vem para casa?". No dia em que a criança finalmente saiu do abrigo, comemoramos! "E, é isso aí gente. Por que então, Maria teve a necessidade de sequestrar o próprio filho?"

\section{Considerações finais}

A narrativa dos quatro casos nos aponta um denominador comum: todas as quatro famílias são pobres! Ou seja, judicializar os casos é um processo de judicialização da pobreza. Ao nos aproximarmos das mulheres gestantes percebemos que a fragilidade das políticas públicas de garantia de direitos e os estigmas em relação ao uso de álcool e outras drogas contribuem diretamente para que elas tenham seus filhos recolhidos compulsoriamente.

Portanto, sustentar uma política de álcool e outras drogas mediada pela conscientização das diversas estratégias para se fazer o uso protegido de substâncias psicoativas, em detrimento de uma política proibicionista, é fundamental para o enfrentamento da violência de gênero. A construção de um modelo de legalização e regulamentação do uso de drogas pode apontar alternativas ao Estado, até então, punitivista; que encarcera e recolhe compulsoriamente os filhos de mulheres pobres, em sua maioria negras. Violências legitimadas a partir do discurso da "guerra às drogas".

A participação do Consultório de Rua no acompanhamento de mulheres gestantes 
usuárias de drogas, evidencia a necessidade da ampliação da oferta de cuidado e garantia de direitos para que as mulheres possam ressignificar o momento da gestação e ter condições subjetivas e materiais para criar seus filhos. Uma das políticas fundamentais é a habitacional, tendo em vista que o déficit habitacional em Belo Horizonte é de mais de 78 mil moradias ${ }^{9}$ e que muitas mulheres perdem o poder familiar por não terem acesso ao direito a uma moradia digna, ficando claro, mais uma vez, o recorte da criminalização da pobreza.

Nesse contexto, o Consultório de Rua, atua como um dispositivo potente para alcançar os sujeitos que estão mais vulneráveis na cidade e com menos direitos garantidos. É um serviço que ensina à rede pública que a via de acesso a esse público é por uma oferta de cuidado, que considera o saber e o desejo dos sujeitos acompanhados, sem recuar frente ao que a sociedade nomeia como pior. E, como bem relatou Silva: ${ }^{6}$

Temos aprendido, a cada dia e com cada usuário, que o que toca a flor da pele convulsiona, aperta o peito e faz delirar meninos, mendigos, malucos, bandidos, santos, padres e juízes, não pede remédios, pede pensamento. Solicita mais poesia, mais arte, mais cultura, mais sublimação, direitos e contornos. Grades e prisões são dispensáveis. Para o humano, o que produz humanidade não é a grade, mas o Outro: seu desejo, seu corpo, cheiro, suas palavras, seu afeto e aconchego. É o laço com o Outro e com a rede - invenção que se faz com homens, ideias e afetos para fazer caber homens, ideias e afetos - o que permite a construção de saídas possíveis. $^{6: 211}$

Ou seja, para as mulheres gestantes das cenas de uso, ofertamos o laço para que juntos possamos desatar os vários nós que perpassam suas vidas ao longo do caminho. 0 nosso olhar se apresenta para além do abdômen preenchido, como já nos ensinou uma trabalhadora da rede. É o sujeito mulher, construindo a maternidade possível que nos interessa. É a partir disso, que se constrói a possibilidade de adesão à oferta de cuidado, evitando nos pautar no modelo de maternidade ideal constituída pelo patriarcado. Trabalhamos com o Real, com a maternidade possível, cheia de contradições, alegrias, sofrimento e dor, assim como toda a extensão da condição humana.

\section{Notas}

\footnotetext{
I Trabalhadores da rede SUS de Belo Horizonte-BH/MG. E-mail de todos os autores: coordenacaoconsultorionarua@ pbh.gov.br.

"Nome fictício.

III Nome fictício.

Iv Nome fictício.

`Este caso se trata uma adaptação da transcrição da comunicação de Brenda Cecília, realizada no dia 4 de agosto de 2017, sobre o tema "o recolhimento dos bebês das mulheres usuárias de drogas e/ou em situação de rua". O evento foi uma atividade do Ateliê Intervalo de Redução de Danos em parceria com a Rede de Observatórios de Políticas e Cuidado em Saúde, que contou com a presença de Emerson Merhy e 40 pesquisadores de todo o Brasil.
} 
v1 Mostrou-se uma fotografia no slide show em que Maria está com seu filho nos braços, sua família e a equipe do Consultório de Rua reunida em frente à van do serviço. Todos em espírito de comemoração.

VII Centro de Referência em Assistência Social.

vIII Centro de Referência em Saúde Mental e em Álcool e outras Drogas.

\section{Referências}

${ }^{1}$ Buarque C. O meu guri. [citado 25 nov 2017]. Disponível em: https://www.letras. mus.br/chico-buarque/66513/.

${ }^{2}$ Karam ML. Proibição às drogas e violação a direitos fundamentais. [citado 25 nov 2017]. Disponível em: http://www.leapbrasil.com.br/media/uploads/texto/72_Proibi\%C3\%A7\% C3\%A30\%20\%C3\%A0s\%20drogas\%20e \%20viola\%C3\%A7\%C3\%A3o\%20a\%20direitos\%20fun damentais\%20-\%20Piau\%C3\%AD.pdf?1376532185

${ }^{3}$ Reis RF. O genocídio dos adolescentes negros no município de Belo Horizonte: Quem importa? [dissertação] Belo Horizonte: Universidade Federal de Minas Gerais; 2017.

${ }^{4}$ Merhy EE. Proposta: Criação de Observatório Microvetorial de Políticas Públicas em Saúde e Educação em Saúde. Projeto apresentado pela UFRJ ao MCTI para concorrer na Chamada MCTI/CNPq/CT-Saúde/MS/SCTIE/Decit No 41/2013 - Rede Nacional de pesquisas sobre Política de Saúde: Conhecimento para Efetivação do Direito Universal à Saúde. Rio de Janeiro: UFRJ; 2013.

${ }^{5}$ Lacadée P. L'enfer, les anges et l'idiot. [Internet] Belo Horizonte, 2014. [citado 25 nov 2017]. Disponível em: http://www.encontrocampofreudiano.org.br/2014/11/lenfer-les-anges-et-lidiot.htm

${ }^{6}$ Silva R A. No meio do caminho, sempre haverá uma pedra. Responsabilidades. 2011 2012; 1(2):203-214. [Internet]. 2011 [citado 02 nov 2017]. Disponível em:http://www8.tjmg. jus.br/presidencia/programanovosrumos/pai_pj/revista/ edicao02/3.pdf.

${ }^{7}$ Portaria no 3/VCIJBH, de 22 de julho de 2016. Dispõe sobre o procedimento para encaminhamento de crianças recémnascidas e dos genitores ao Juízo da Infância e da Juventude, assim como, oitiva destes, nos casos de graves suspeitas de situação de risco, e sobre o procedimento para aplicação de medidas de proteção. Diário do Judiciário Eletrônico TJMG. [Internet] 201625 jul [citado 04 mai 2017]:29-33. Disponível em: http://ftp.tjmg.jus.br/juridico/diario/index.jsp?dia $=2207 \&$ completa=2inst\%7Cadm.

${ }^{8}$ Moraes V. A casa. [citado 9 set 2016]. Disponível em: https://www.letras. mus.br/vinicius-de-moraes/4925

${ }^{9}$ Ministério das Cidades (BR), Secretaria Nacional de Habitação, Fundação João Pinheiro. Déficit Habitacional Municipal no Brasil 2010 [Internet]. [citado 04 maio 2017]. Disponível em: http://www.fjp.mg.gov.br/index.php/docman/cei/ deficithabitacional/216-deficit-habitacion al-municipal-no-brasil-2010/file 